\title{
BIODEGRADAÇÃO DO HERBICIDA 2,4-D UTILIZANDO BACTÉRIAS SELECIONADAS DO SOLO DO CERRADO MARANHENSE
}

\begin{abstract}
O presente trabalho visou avaliar a biodegradação do herbicida 2,4 diclorofenoxiacético (2,4-D) por linhagens bacterianas isoladas de solo do Cerrado Maranhense. Os micro-organismos selecionados para biodegradação do herbicida 2,4-D em meios de cultura sólidos mostraram-se eficazes. As linhagens bacterianas oriundas do solo de cultivo de feijão (F5 e F7) e de mandioca (M5 e M6) foram as que melhor se adaptaram aos meios de cultura contendo o herbicida. Quando se adicionou fonte extra de carbono e nitrogênio verificouse melhor crescimento dos micro-organismos na presença de 2,4-D. Todos os micro-organismos foram eficazes na inativação do herbicida, sendo a linhagem F7 a que apresentou maior percentual de biodegradação do 2,4-D (92 \%).
\end{abstract}

* Doutorando em Tecnologia de Processos Químicos e Bioquímicos, Universidade Federal do Rio de Janeiro, Escola de Química (UFRJ/EQ), Rio de Janeiro, RJ (e-mail: lindomarc@eq.ufrj.br).

** Doutor em Química, Universidade Estadual do Maranhão, Centro de Estudos Superiores de Imperatriz (UEMA/CESI), Imperatriz, MA (e-mail: fabioufv@hotmail.com). 


\section{INTRODUÇÃO}

A utilização de agrotóxicos tem aumentado a preocupação com a poluição ambiental, principalmente a poluição do solo. Entre os agrotóxicos, os herbicidas são os produtos mais comercializados no mundo em face da necessidade de controle de ervas indesejável na agricultura (ARAÚJO, 2002). O Brasil conta com grandes extensões agrárias e terras aptas para o cultivo, encontrando-se entre os maiores consumidores de agrotóxicos mundiais (GALLI et al., 2006). O aumento do uso desses produtos químicos de forma descontrolada pode contribuir para a poluição ambiental.

O ácido 2,4-diclorofenoxiacético (2,4-D) destaca-se entre os herbicidas por ser um dos mais empregados no setor agrícola (MERINI et al., 2007). Esse herbicida altamente seletivo, sistêmico e pós-emergente, é bastante utilizado na região Sul do Maranhão em diversas culturas agrícolas. Segundo Higarashi (1999), o 2,4-D pertence à família dos organoclorados, que são compostos extremamente tóxicos e que apresentam longa persistência. Entre seus produtos de degradação, o 2,4-diclorofenol (2,4-DCF) ostenta toxicidade maior que o próprio 2,4-D. Tratando-se de um dos herbicidas de maior consumo no Brasil, o controle do seu destino no ambiente assume fundamental importância para a preservação de solos e da água potável (VIANEZ JUNIOR, 2007; BERNARD et al., 2005; PRADO, 2001; PRADO e AIROLDI, 2001; WAITE et al., 2002). A elevada toxicidade desse herbicida e de seu produto de degradação exige que se encontrem formas de eliminá-lo sem causar e/ou minimizar seus danos ao ambiente.

A degradação biológica da molécula do contaminante (herbicida) em produtos menos tóxicos representa uma das formas de proteger o ambiente e de recuperar locais já contaminados. Nesse processo, denominado de biorremediação, a molécula degrada-se completamente a moléculas inorgânicas de ocorrência universal, como $\mathrm{CO}_{2}, \mathrm{CO}, \mathrm{H}_{2} \mathrm{O}, \mathrm{NH}_{3}, \mathrm{H}_{2} \mathrm{~S}$ e $\mathrm{HCL}$ (MELO e AZEVEDO, 2008). A biorremediação constitui solução eficaz e tem despertado o interesse de vários pesquisadores (DOELMAN e BREEDVELK, 1999; FREIRE et al. 2000; BRITO, 2004; CELIS, ELEFSINIOTIS e SINGHAL, 2008; BAELUM, JACOBSEN e HOLBEN, 2010; GONZALÉZ et al., 2012).

O processo de biorremediação de herbicidas no solo é mediado por micro-organismos, dentre os quais as bactérias, podendo variar de apenas dias até anos para que ocorra o completo desaparecimento da molécula (GAYLARD, BELLINASO e MANFIO, 2005). Nesse sentido, a inoculação de micro-organismos previamente selecionados para aumentar a velocidade de degradação vem sendo apontada como alternativa de recuperação de ambientes poluídos (FRANCO et al., 1992). A utilização de micro-organismos na biorremediação tem se mostrado eficiente para biodegradar moléculas xenobióticas (estranhas ao ambiente natural) e recalcitrantes (de difícil degradação), devido sua capacidade para reciclar várias moléculas da biosfera, participando de diversos ciclos dos elementos químicos (GAYLARD, BELLINASO e MANFIO, 2005).

A biodegradação dos herbicidas sofre influência das propriedades quantitativas e qualitativas da comunidade microbiana do solo, a qual definirá maior ou menor cota de degradação, além da disponibilidade do composto para os micro-organismos. Segundo Araújo (2002), a ação de micro-organismos sobre os herbicidas constitui mecanismo da maior importância, pois a degradação microbiológica, na maioria dos casos, contribui para a dissipação da molécula no ambiente.

A maioria dos estudos consultados sobre os efeitos de agrotóxicos em micro-organismos do solo envolve experimentos de laboratório voltados para a aplicação de determinado composto. No campo, um ou mais agrotóxicos podem ser repetidamente aplicados no mesmo solo por vários anos e deixar resíduos com efeitos danosos sobre a biomassa microbiana.

O presente trabalho visou avaliar a degradação biológica do herbicida 2,4-D por linhagens bacterianas, isoladas de solo do Cerrado Maranhense. 


\section{MATERIAL E MÉTODOS}

\subsection{AMOSTRAS DE SOLOS}

As amostras de solos, oriundas de cultivo de feijão e mandioca, foram coletadas no município de Imperatriz (MA), situado no Cerrado Maranhense. As coletas ocorreram em diferentes pontos de áreas com e sem histórico de aplicação do herbicida 2,4-D, nas profundidades de 0 a 5 e 5 a $20 \mathrm{~cm}$ (horizonte A), retirando-se a cobertura vegetal. Os solos foram peneirados em peneira malha de $2 \mathrm{~mm}$, acondicionados em sacos plásticos e mantidos à temperatura de $4{ }^{\circ} \mathrm{C}$ em geladeira até o momento das análises, realizadas no Laboratório de Microbiologia Ambiental do Centro de Estudos Superiores de Imperatriz (CESI/UEMA).

\subsection{HERBICIDA}

Utilizou-se o herbicida 2,4-D (ácido 2,4-diclorofenoxiacético) mais associações, aplicando a sua formulação técnica nas dosagens recomendadas para condições de campo (WHOLTING e HANCE, 1991).

\subsection{SELEÇÃO DE BACTÉRIAS APTAS À DEGRADAÇÃO DO HERBICIDA 2,4-D}

\subsubsection{Crescimento de linhagens bacterianas com potencial de degradação de 2,4-D em meio de cultura sólido}

Os isolamentos ocorreram por meio de testes de crescimento em meio mineral J.E. sólido, segundo Jones e Edington (1968): $\left(\mathrm{K}_{2} \mathrm{HPO}_{4}=0,5 \mathrm{~g} ;\left(\mathrm{NH}_{4}\right)_{2} \mathrm{SO}_{4}=0,5 \mathrm{~g} ; \mathrm{MgSO}_{4} \cdot 7 \mathrm{H}_{2} \mathrm{O}=\right.$ $0,5 \mathrm{~g} ; \mathrm{FeCl}_{2} \cdot 1 \mathrm{H}_{2} \mathrm{O}=10 \mathrm{mg} ; \mathrm{CaCl}_{2}=10 \mathrm{mg} ; \mathrm{MnCl}_{2}=0,1 \mathrm{mg} ; \mathrm{ZnSO}_{4}=0,01 \mathrm{mg}$; ágar $=15,0 \mathrm{~g}$ por litro de água destilada + 2,4-D $\left(20 \mu \mathrm{g} \mathrm{mL}^{-1}\right)$. A avaliação durou 96 horas após a inoculação em meio sólido (em placa de petri).

As linhagens bacterianas que apresentaram melhor crescimento no meio com 2,4-D como única fonte de carbono foram selecionadas para o estudo da cinética de crescimento. As linhagens foram submetidas à avaliação de crescimento em meio mineral $\mathrm{M} 9$, contendo por litro: $\mathrm{Na}_{2} \mathrm{HPO}_{4}=6,0 \mathrm{~g} ; \mathrm{KH}_{2} \mathrm{PO}_{4}=3,0 \mathrm{~g} ; \mathrm{NaCl}=0,5 \mathrm{~g} ; \mathrm{MgSO}_{4} \cdot 7 \mathrm{H}_{2} \mathrm{O} 0,1 \mathrm{M}=10 \mathrm{~mL} ; \mathrm{CaCl}_{2} 1 \mathrm{M}=10 \mathrm{~mL}$; ágar $=15,0 \mathrm{~g})+2,4-\mathrm{D}$ na concentração de $20 \mu \mathrm{g} \mathrm{mL}-1$ (em placa de petri), durante 168 horas de incubação à temperatura de $28^{\circ} \mathrm{C}$ (SAMBROOK, FRITHSCH e MANIATIS, 1989; ROQUE e MELO, 2000).

\subsection{CRESCIMENTO DAS LINHAGENS BACTERIANAS EM MEIO DE CULTURA LÍQUIDA}

\subsubsection{Avaliação da cinética de crescimento de linhagens bacterianas com potencial de degradação de 2,4-D em meio de cultura líquido}

As linhagens selecionadas para o teste de crescimento em meio de cultura sólido foram cultivadas em meio de cultura líquido Luria Bertani $(\mathrm{LB})$, contendo $(\mathrm{g} / \mathrm{L})$ : triptona $=10$, extrato de levedura $=5 \mathrm{e} \mathrm{NaCl}=5 \mathrm{em}$ tubos de $10 \mathrm{~mL}$, durante 24 horas (SAMBROOK, FRISTHSCH e MANIATIS, 1989). Após esse período, $100 \mu \mathrm{L}$ de cada linhagem bacteriana selecionada e cultivadas em meio de cultura LB foram inoculados em meio mineral J.E. (JONES e EDINGTON, 1968), acrescido de $20 \mu \mathrm{g} \mathrm{mL}^{-1}$ de 2,4 -D, em intervalos de 12 e 12 horas. Após o pré-cultivo, $1 \mathrm{~mL}$ do inóculo 
de cada bactéria isolada e com potencial de degradação do herbicida foi adicionado em $100 \mathrm{~mL}$ de meio mineral J.E. suplementado com 2,4-D $\left(20 \mu \mathrm{g} \mathrm{mL}^{-1}\right)$. As avaliações da cinética de crescimento foram realizadas pela absorbância em espectrofotômetro Femto $800 \mathrm{XI}(560 \mathrm{~nm})$, mediante leituras a cada 24 horas durante o período total de 168 horas (ANDRIGHETTI, 2011; ROQUE e MELO, 2000).

\subsubsection{Crescimento de linhagens bacterianas com potencial de degradação de 2,4-D utilizando diferentes fontes de carbono e nitrogênio}

As linhagens selecionadas foram utilizadas para verificar a influência da fonte de carbono e de nitrogênio no crescimento bacteriano em meio de cultura mineral J.E. (JONES e EDINGTON, 1968), suplementado ou não com fonte extra de carbono (glicose), com ou sem fonte de nitrogênio da seguinte maneira:

a) Meio mineral J.E. + 2,4-D nas concentrações 20,50 e $100 \mu \mathrm{gL}^{-1}$;

b) Meio mineral J.E. + 2,4-D (20,50, e $\left.100 \mu \mathrm{gL}^{-1}\right)+$ glicose $(0,5 \%)$;

c) Meio mineral J.E. $+\mathrm{NH}_{4} \mathrm{NO}_{3}+2,4-\mathrm{D}(20,50,100 \mu \mathrm{g} \mathrm{mL}-1)+$ glicose $(0,5 \%)$.

Os experimentos foram avaliados durante 168 horas em intervalos de análise de 24 horas. A produção do inóculo e a montagem dos experimentos foram desenvolvidas de acordo com o descrito no item anterior. Em cada intervalo avaliou-se o crescimento mediante leitura da absorbância $(560 \mathrm{~nm})$ em espectrofotômetro Femto 800 XI (ROQUE e MELO, 2000).

\subsection{BIODEGRADAÇÃO DO HERBICIDA 2,4-D EM LABORATÓRIO E IDENTIFICAÇÃO DAS BACTÉRIAS SELECIONADAS}

Realizou-se a análise do herbicida no experimento de biodegradação empregando cromatógrafo a gás GC17-A, equipado com injetor split/splitless e detector por captura de elétrons (Shimadzu).

A separação do herbicida e do padrão interno ocorreu em coluna capilar DB-5, 0,25 mm x $30 \mathrm{~m}$, espessura do filme de $0,25 \mu \mathrm{m}$ (J \& W Scientific), com programação de temperatura iniciando em $180^{\circ} \mathrm{C}$ ( $5 \mathrm{~min}$ ) e finalizando em $255^{\circ} \mathrm{C}$, com aquecimento gradual de $25^{\circ} \mathrm{C} / \mathrm{min}$. As temperaturas do vaporizador e do detector foram estabelecidas em 220 e $225^{\circ} \mathrm{C}$, respectivamente. Empregouse nitrogênio como gás de arraste, na vazão total de $22 \mathrm{~mL} / \mathrm{min}$. Operou-se o injetor no modo split, sendo injetado o volume de $2 \mu \mathrm{L}$. Os picos foram analisados em integrador Shimadzu, modelo CR6-A e a identificação das bactérias efetuada pelo método de coloração de Gram de Hucker, de acordo com o procedimento descrito por Murray, Doetsch e Robinow (1994).

\section{RESULTADOS E DISCUSSÃO}

\subsection{SELEÇÃO DE BACTÉRIAS APTAS À DEGRADAÇÃO DO HERBICIDA 2,4-D}

As linhagens bacterianas foram selecionadas com base em observações macroscópicas de crescimento em meio mineral J.E. e em meio mineral M9 sólido, suplementado com o herbicida 2,4-D em diferentes concentrações, além das suas características morfológicas, escolhendo-se colônias diferentes e evitando purificar aquelas com crescimento lento e irregular (Tabelas 1 e 2). 
TABELA 1 - AVALIAÇÃO DO CRESCIMENTO DE LINHAGENS BACTERIANAS EM MEIO J.E. SÓLIDO, SUPLEMENTADO COM 2,4-D NA CONCENTRAÇÃO DE $20 \mu \mathrm{g} \mathrm{mL}$-1, $^{-1}$ APÓS 96 HORAS DE INCUBAÇÃO

\begin{tabular}{c|c|c|c}
\hline LINHAGENS & $\begin{array}{c}\text { CRESCIMENTO } \\
\text { MICROBIANO }\end{array}$ & LINHAGENS & $\begin{array}{c}\text { CRESCIMENTO } \\
\text { MICROBIANO }\end{array}$ \\
\hline $\mathrm{F} 1$ & -- & M1 & -- \\
\hline $\mathrm{F} 2$ & + & $\mathrm{M} 2$ & -- \\
\hline $\mathrm{F} 3$ & -+ & $\mathrm{M} 3$ & -+ \\
\hline $\mathrm{F} 4$ & -+ & $\mathrm{M} 4$ & ++ \\
\hline $\mathrm{F} 5$ & ++ & $\mathrm{M} 5$ & ++ \\
\hline $\mathrm{F} 6$ & + & $\mathrm{M} 6$ & + \\
\hline $\mathrm{F} 7$ & ++ & $\mathrm{M} 7$ & + \\
\hline $\mathrm{F} 8$ & + & $\mathrm{M} 8$ & + \\
\hline $\mathrm{F} 9$ & -+ & $\mathrm{M} 9$ & + \\
\hline
\end{tabular}

-- Pouco crescimento; -+ Crescimento razoável; + Crescimento satisfatório; ++ Ótimo crescimento.

TABELA 2 - AVALIAÇÃO DO CRESCIMENTO DE LINHAGENS BACTERIANAS EM MEIO MINERAL M9 SÓLIDO, SUPLEMENTADO COM 2,4-D NA CONCENTRAÇÃO DE $20 \mu \mathrm{g} \mathrm{mL}{ }^{-1}$, APÓS 168 HORAS DE INCUBAÇÃO

\begin{tabular}{|c|c|c|c|}
\hline LINHAGENS & $\begin{array}{l}\text { CRESCIMENTO } \\
\text { MICROBIANO }\end{array}$ & LINHAGENS & $\begin{array}{c}\text { CRESCIMENTO } \\
\text { MICROBIANO }\end{array}$ \\
\hline $\mathrm{F} 1$ & -+ & M1 & -- \\
\hline $\mathrm{F} 2$ & + & M2 & -+ \\
\hline F3 & -+ & M3 & - \\
\hline $\mathrm{F} 4$ & -+ & M4 & + \\
\hline F5 & ++ & M5 & ++ \\
\hline F6 & -+ & M6 & ++ \\
\hline $\mathrm{F} 7$ & ++ & M7 & ++ \\
\hline F8 & + & M8 & + \\
\hline F9 & -+ & M9 & + \\
\hline
\end{tabular}

-- Pouco crescimento; -+ Crescimento razoável; + Crescimento satisfatório; ++ Ótimo crescimento.

Conforme os resultados obtidos, as linhagens bacterianas isoladas do solo com cultivo de feijão (F5, F7) e mandioca (M5 e M6) apresentaram melhor crescimento nos meios de culturas J. E. e M9 suplementados com 2,4-D. Por esse motivo, somente os resultados dessas linhagens serão apresentados a seguir. A eficácia de degradação de compostos orgânicos por micro-organismos, cientificamente reconhecida, tem levado vários pesquisadores a isolar micro-organismos capazes de degradar agrotóxicos em diversos ambientes como, solos agrícolas e águas residuais (SMEJKAL et al., 2001; WIDEHEM et al., 2002; BENIMELI et al., 2007). 


\subsection{CRESCIMENTO DAS LINHAGENS BACTERIANAS \\ EM MEIO DE CULTURA LÍQUIDA}

Na Figura 1 mostra-se o crescimento das linhagens bacterianas em meio suplementado com o herbicida 2,4-D nas concentrações de 20, 50 e $100 \mu \mathrm{g} \mathrm{mL}^{-1}$.
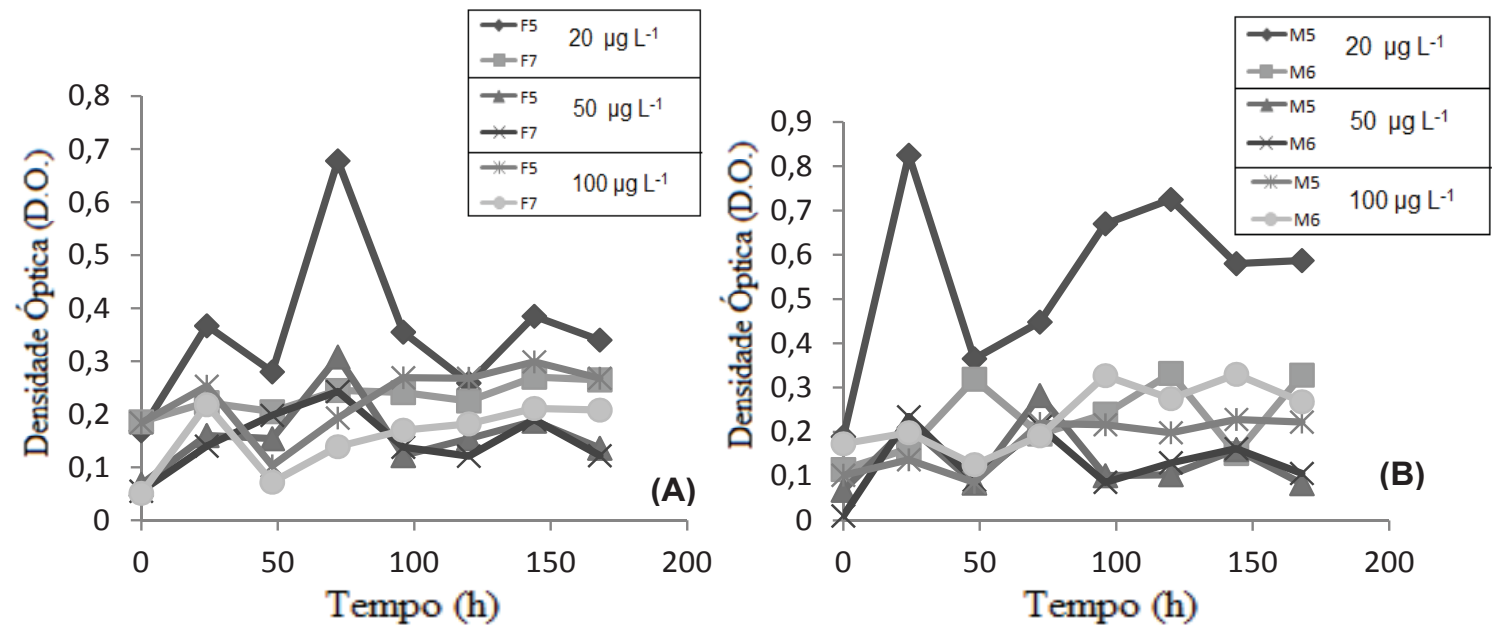

\section{FIGURA 1 - CRESCIMENTO DAS LINHAGENS MICROBIANAS ISOLADAS DE SOLOS COM CULTIVO DE FEIJÃO (A) E MANDIOCA (B) EM MEIO MINERAL J. E. SUPLEMENTADO COM O HERBICIDA 2,4-D EM DIFERENTES CONCENTRAÇÕES (20, 50 e $\left.100 \mu \mathrm{g} \mathrm{L}^{-1}\right)$}

O crescimento bacteriano representa variável importante a ser considerada para avaliar a degradação biológica e o potencial dos micro-organismos em metabolizar a molécula do contaminante (herbicida). A Figura 1 evidencia que as linhagens microbianas F5 e M5 apresentaram melhor crescimento em meio mineral J. E. suplementado com $20 \mu \mathrm{g} \mathrm{mL}^{-1}$ do herbicida 2,4-D e crescimento máximo em 72 e 24 horas, respectivamente. Nos ensaios contendo concentrações maiores $(50 \mathrm{e}$ $100 \mu \mathrm{g} \mathrm{mL}^{-1}$ ), o crescimento mostrou-se menor. Segundo Prado e Airold (2001), o herbicida 2,4 D atua diretamente sobre os micro-organismos do solo. Inicialmente a população utiliza o herbicida como fonte de nutriente e em seguida com o aumento da quantidade do herbicida aplicada ocorre decréscimo na atividade microbiana.

Shaler e Klecka (1986) estudaram a biodegradação de 2,4-D empregando cultura bacteriana capaz de utilizar o herbicida como a única fonte de carbono. A biodegradação completa de $20 \mathrm{mg} \mathrm{L}^{-1}$ de 2,4-D foi realizada em 36 horas. Zipper et al. (1999) avaliaram a biodegradação do herbicida 2,4-D nas concentrações de 20 e $80 \mathrm{mg} \mathrm{L}^{-1}$, utilizando culturas oriundas de lodo de esgoto. Observaram que a degradação iniciou após a fase de latência de $125 \mathrm{~h}$, sendo concluída em 35 horas.

Na Figura 2 ( $A$ e B) nota-se que as linhagens microbianas apresentaram fase de crescimento a partir da qual foi atingido o seu valor máximo em 48 e 96 horas para as bactérias oriundas de solo de cultivo de feijão e de mandioca (F5, M6), respectivamente, na concentração de $20 \mu \mathrm{gL}^{-1}$ do 2,4 D. Com a adição de fonte extra de carbono (glicose) houve estímulo ao crescimento das linhagens bacterianas em todas as concentrações. Tal fato pode ser observado comparando-se esses resultados com os dados da Figura 1, quando não houve adição de fonte extra de carbono.

De acordo com a Figura 2 ( $C$ e D), as linhagens bacterianas também apresentaram melhor desenvolvimento no meio de cultura contendo fonte de nitrogênio. $O$ estudo da cinética microbiana evidenciou a importância da fonte de nitrogênio e de carbono para a biodegradação. Os resultados mostram que a adição de fonte extra de carbono (glicose) e de nitrogênio $\left(\mathrm{NH}_{4} \mathrm{NO}_{3}\right)$ estimulou o crescimento microbiano por meio da atividade catabólica. A presença do 2,4-D, com ou sem outra 
fonte de carbono ou de nitrogênio, representou o fator seletivo para a ocorrência do crescimento das linhagens microbianas. Essa característica pode estar relacionada com a presença de moléculas orgânicas semelhantes às moléculas xenobióticas no solo. A utilização intensiva de herbicidas também pode promover a seleção dos micro-organismos capazes de biodegradar o composto xenobiótico.
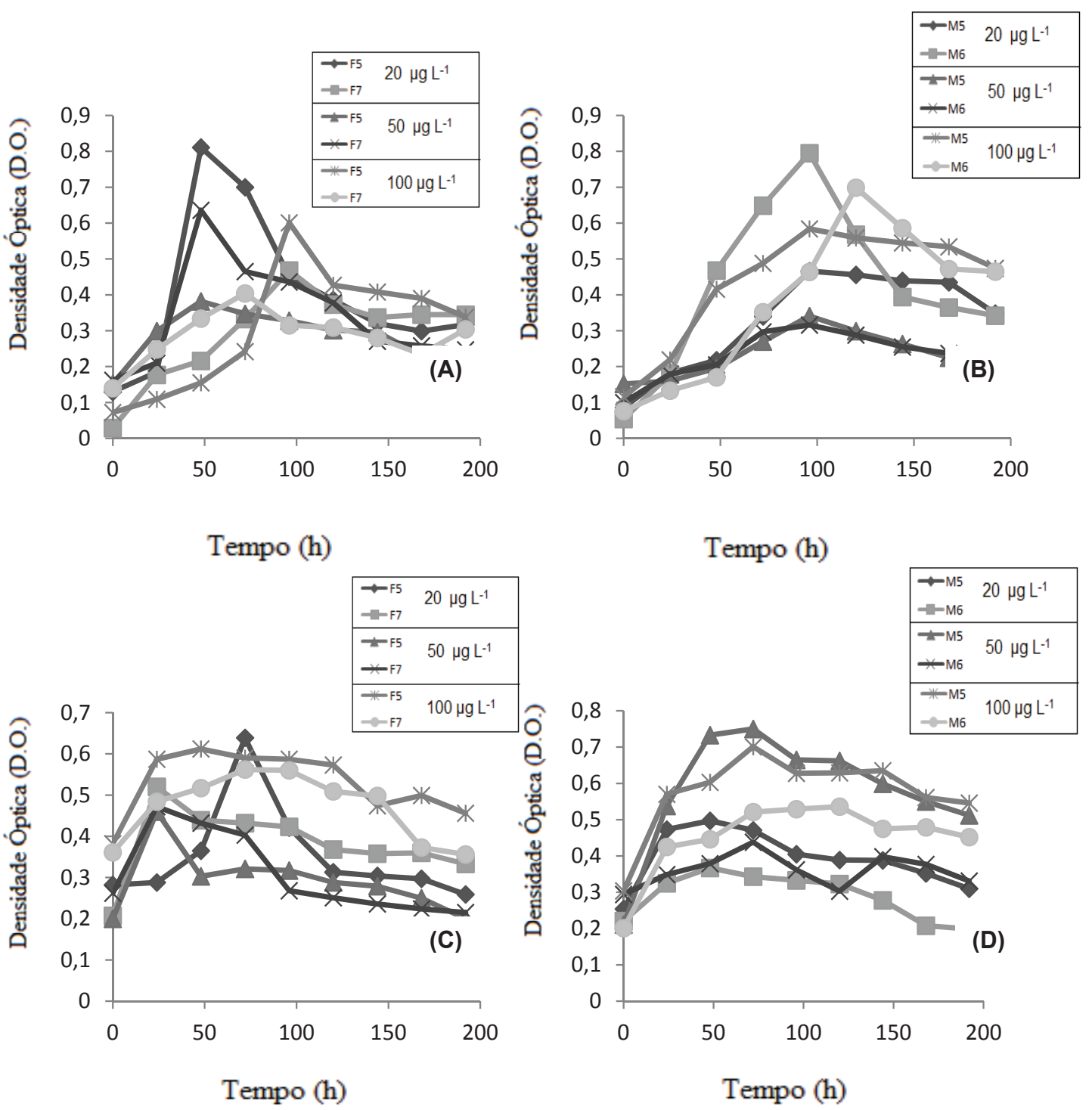

\section{FIGURA 2 - CRESCIMENTO DAS LINHAGENS MICROBIANAS ISOLADAS DE SOLOS COM CULTIVO DE FEIJÃO (A, C) E MANDIOCA (B, D) EM MEIO MINERAL J. E. COM O HERBICIDA 2,4 D (A E B = SUPLEMENTADO COM GLICOSE; C E D = SUPLEMENTADO COM GLICOSE E NITROGÊNIO)}

Alguns autores mencionaram que a adição de minerais ou de fontes de carbono pode ser utilizada para aumentar o grau de degradação de xenobióticos, incluindo bifenilos policlorados (BEDARD e HABERL, 1990), piretroides sintéticos (GRANT e BETTS, 2001) e o ácido 2,4-diclorofenoxiacético (PAPANASTASIOU e MAIER, 1982).

Para Limbert e Betts (1994), caso o agrotóxico presente no meio não tenha sido suficiente para ativar sua biodegradação, a degradação pode ser melhorada com a presença de outro substrato. O micro-organismo pode optar pelo uso do substrato complementar como fonte de energia até à adaptação necessária para a degradação do agrotóxico (DALTON e STIRLING, 1982; HARDER e DIJKHUIZEN 1982). 
Vários autores relataram que a adição extra de carbono em solo contaminado com xenobióticos estimula a mineralização da molécula contaminante pela população microbiana indígena do local e que solos com histórico de aplicação de herbicidas podem apresentar maior capacidade de mineralização que solos sem históricos de aplicação (OSTROFSKY et al., 2001; SILVA et al., 2004).

Apesar dos solos com histórico de aplicação de agrotóxicos apresentarem maior capacidade de degradação do herbicida em produtos menos tóxicos, o processo pode se estender por longo espaço de tempo. A biodegradação das moléculas em períodos mais longos não é interessante devido à possibilidade de contaminação de outros locais mediante lixiviação do solo (SILVA et al., 2004; LIMA et al., 2009). Assim, vários trabalhos têm sido direcionados para o isolamento de micro-organismos que sejam capazes de realizar a transformação do herbicida em produtos menos tóxicos de forma mais rápida visando acelerar o processo de descontaminação (MANDELBAUM, WACKETT e ALLAN, 1993; MANDELBAUM, ALLAN e WACKETT, 1995; RADOSEVICH et al., 1995; STRONG et al., 2002; SHAPIR et al., 2007).

\subsection{BIODEGRADAÇÃO DO HERBICIDA 2,4-D EM LABORATÓRIO E IDENTIFICAÇÃO DAS BACTÉRIAS SELECIONADAS}

O experimento de biodegradação do herbicida 2,4-D $\left(100 \mu \mathrm{g} \mathrm{mL}{ }^{-1}\right)$, com inoculação das linhagens microbianas F5, F7, M5 e M7 foi realizado em triplicata e comparado ao controle sem células microbianas.

De acordo com a Tabela 3, todas as linhagens selecionadas apresentaram biodegradação acima de $80 \%$. A linhagem F7 mostrou maior porcentagem de inativação do herbicida 2,4-D (92\%), devido melhor adaptação e sua utilização como fonte de nutriente. O produto de degradação 2,4-DCF não foi detectado em nenhuma das amostras analisadas. Nesse intervalo de tempo, o processo de biodegradação nas condições testadas foi altamente satisfatório, sendo essencial para a produção das enzimas responsáveis pela degradação e/ou para a difusão do contaminante através da membrana celular.

TABELA 3 - RESULTADOS DA BIODEGRADAÇÃO DO HERBICIDA 2,4-D APÓS
96 HORAS DE INOCULAÇÃO

\begin{tabular}{c|c|c}
\hline \multirow{2}{*}{ Linhagens Microbianas } & 2,4 D & 2,4 DCF de Biodegradação do Herbicida \\
\hline F5 & 85 & $<$ Limite de Detecção \\
\hline F7 & 92 & $<$ Limite de Deteção \\
\hline M5 & 81 & $<$ Limite de Detecção \\
\hline M6 & 86 & $<$ Limite de Deteç̧ão \\
\hline
\end{tabular}

De acordo com a Figura 3, as linhagens F5, F7, M5 e M6 em conformidade com a técnica de Coloração de Gram foram classificadas como bactérias Gram-Positivas, apresentando forma e arranjo de estafilococos. 

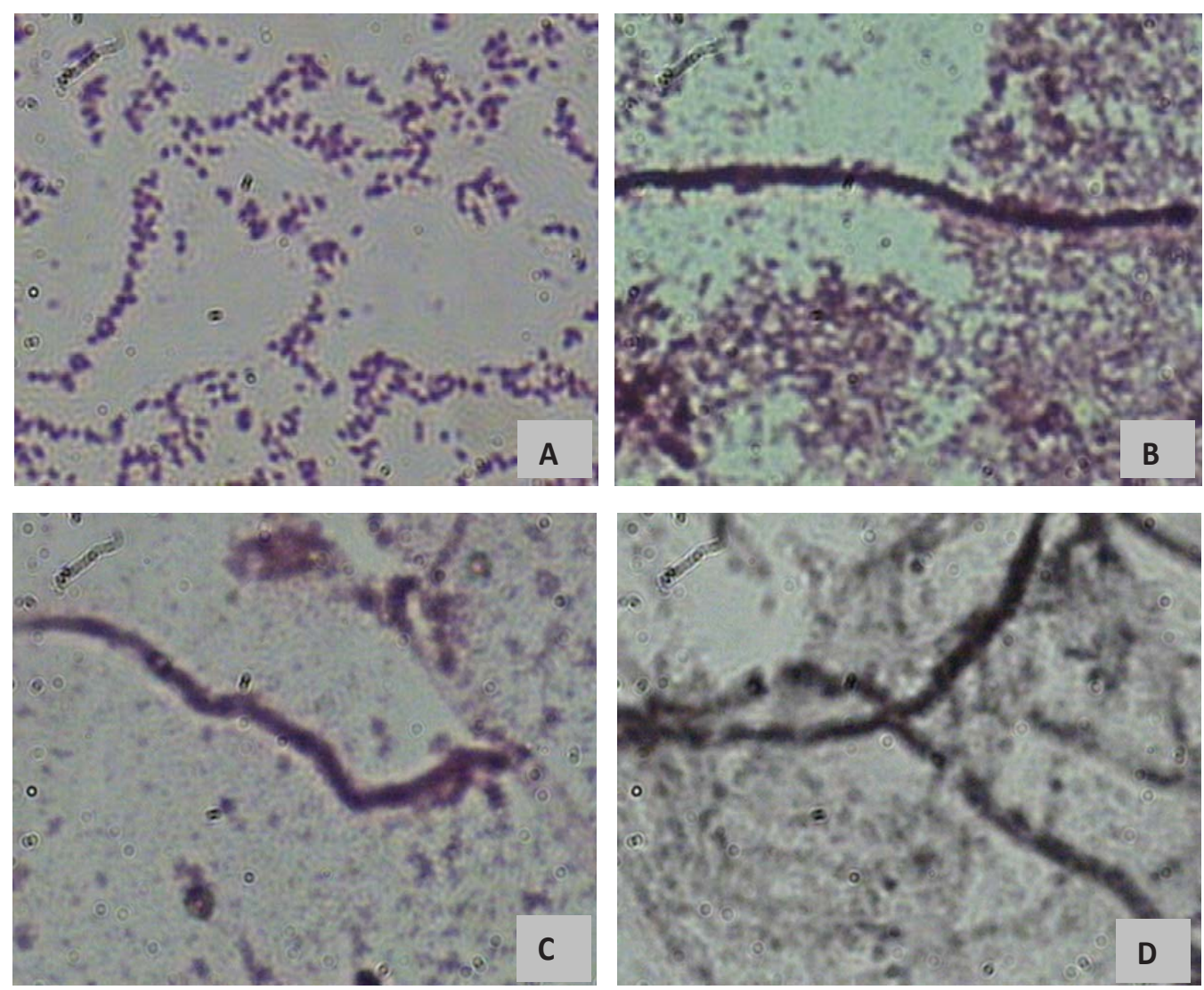

\section{FIGURA 3 - CLASSIFICAÇÃO DAS LINHAGENS MICROBIANAS PELO MÉTODO DE COLORAÇÃO DE GRAM: (A) F5, (B) F7, (C) M5 e (D) M6}

\section{CONCLUSÃO}

As linhagens bacterianas isoladas do solo com cultivo de feijão (F5, F7) e mandioca (M5 e M6) apresentaram melhor crescimento nos meios de culturas J. E. e M9 suplementados com 2,4-D.

$\mathrm{Na}$ presença de $\mathrm{NH}_{4} \mathrm{NO}_{3}$ e glicose como fonte de carbono houve estímulo ao crescimento das linhagens de bactérias, sugerindo atividade catabólica na presença de glicose. $\mathrm{O}$ fator seletivo para a ocorrência do crescimento das linhagens microbianas foi a presença do 2,4-D, com ou sem outra fonte de $\mathrm{N}$ ou $\mathrm{C}$.

Todas as linhagens bacterianas selecionadas apresentaram biodegradação do herbicida 2,4-D acima de $80 \%$. A linhagem F7 evidenciou melhor porcentagem de inativação desse herbicida (92 \%), devido maior adaptação e sua utilização como fonte de nutriente.

O produto de degradação 2,4-DCF não foi detectado em nenhuma das amostras analisadas.

De acordo com a técnica de coloração de Gram, todas as linhagens selecionadas para o experimento de biodegradação foram classificadas como bactérias Gram-Positivas, apresentando forma e arranjo de estafilococos.

\section{ABSTRACT \\ BIODEGRADATION OF HERBICIDE 2,4-D USING SELECTED SOIL BACTERIA FROM MARANHÃO'S CERRADO (BRAZIL)}

This study aims to evaluate the biodegradation of 2,4-dichlorophenoxyacetic acid (2,4-D) by bacterial strains 
isolated from country vegetation in Maranhão, Brazil. The microorganisms selected for biodegradation of 2,4-D in solid culture media were effective. The bacterial strains from cultivation soil of bean (F5 and F7) and cassava (M5 and M6) were the best adapted to the culture media containing the herbicide. Microorganism growth was greater in the presence of 2,4-D when extra source of carbon and nitrogen was added. All microorganisms were effective in inactivating the herbicide; the stain F7 showed the greatest percentage of biodegradation of 2,4-D (92\%).

\section{KEY-WORDS: BIODEGRADATION; 2,4-DICHLOROPHENOXYACETIC ACID; HERBICIDES; BACTERIA.}

\section{REFERÊNCIAS}

1 ARAÚJO, A.S.F. Biodegradação, extração e análise de glifosato em dois tipos de solos. 2002. 83 f. Dissertação (Mestrado em Microbiologia Agrícola), Escola Superior de Agricultura Luiz de Queiroz, Piracicaba, 2002.

2 ANDRIGHETTI, M.S. Biodegradação de glifosato por bactérias isoladas de solo cultivados com macieira com diferentes histórico de aplicação deste herbicida. 2011. 109 f. Dissertação (Mestrado em Microbiologia Agrícola e Meio Ambiente), Universidade Federal do Rio Grande do Sul, Porto Alegre, 2011.

3 BAELUM, J.; JACOBSEN, C.S.; HOLBEN, W.E. Comparison of 16S rRNA gene phylogeny and functional tfdA gene distribution in thirty-one different 2,4- dichlorophenoxyacetic acid and 4-chloro-2-methylphenoxyacetic acid degraders. Systematic and Applied Microbiology, v.33, p.67-70, 2010.

4 BEDARD, D.L.; HABERI, M.L. Influence of chlorine substitution pattern on the degradation of polychlorinated biphenyls by eight bacterial strains. Journal of Microbial Ecology, v.20, p.87-102, 1990.

5 BENIMELI, C.S.; GONZÁLEZ, A.J.; CHAILE, A.P.; AMOROSO, M.J. Temperature and pH effect on lindane removal by Streptomyces sp. M7 in soil extract. Journal of Basic Microbiology, v.47, p.468-473, 2007.

6 BERNARD, H.; CHABALIER, P.F.; CHOPART, J.L.; LEQUBE, B.; VAUCLIN, M. Assessment of herbicide leaching risk in two tropical soils of Reunion island (France). Journal of Environmental Quality, v.2, n.34, p.53-54, 2005.

7 BRITO, N.N. et al. Utilização de fungos na remediação de efluentes industriais. In: FÓRUM DE ESTUDOS CONTÁBEIS, 4., 2004, Rio Claro. Anais... Rio Claro: Faculdades Integradas Claretianas, 2004.

8 CELIS, E.; ELEFSINIOTIS, P.; SINGHAI, N. Biodegradation of agricultural herbicides in sequencing batch reactors under aerobic or anaerobic conditions. Water Research, v.42, p.3218-3224, 2008.

9 DALTON, H.; STIRLING, D.I. Co-metabolism. Journal of Royal Society of London, v.297, p.481-496, 1982.

10 DOELMAN, P.; BREEDVELK, G. In situ versus on site practices. In: ADRIANO, D. C. et al. (Ed.). Bioremediation of contaminated soils. Madison: ASA, 1999. p.539-558.

11 FRANCO, A.A.; CAMPELLO, E.F.C.; SILVA, E.M.R.; FARIAS, S.M. Revegetação de solos degradados. Seropédica: EMBRAPA - CNPAB, 1992. $8 \mathrm{p}$.

12 FREIRE, R.S.; PELEGRINI, R.; KUBOTA, L.T.; DURÁN, N.; ZAMORA, P.P. Novas tendências para o tratamento de resíduos industriais contendo espécies organocloradas. Química Nova, São Paulo, v.23, n.4, p.504-511, 2000.

13 GALLI, A.; SOUZA, D.; GARBELLINI, G.S.; COUTINHO, C.F.B.; MAZO, L.H.; AVACA, L.A.; MACHADO, S.A.S. Utilização de técnicas eletroanalíticas na determinação de agrotóxicos em alimentos. Química Nova, v.29, n.1, p.1-14, 2006.

14 GAYLARD, C.C.; BELLINASO, M.L.; MANFIO, G.P. Aspectos biológicos e técnicas da biorremediação de xenobióticos. Biotecnologia, Ciência e Desenvolvimento, Brasília, v. 8, n. 34, jan./jun. 2005. Disponível em: <http://www. biotecnologia.com.br/edicoes/ed34.php>. Acesso em: 12 fev. 2013.

15 GONZÁleZ, A.J; GALLEGO, A.; GEMINI, V.L.; PAPALIA, M.; RADICE, M.; GUTKIND, G.; PLANES, E.; KOROL, S.E. Degradation and detoxification of the herbicide 2,4-dichlorophenoxyacetic acid (2,4-D) by an indigenous Delftia sp. strain in batch and continuous systems. International Biodeterioration \& Biodegradation, v.66, p.8-13, 2012.

16 GRANT, R.J.; BETTS, W.B. Biodegradation of synthetic pyrethroid insecticides in formulated compounds. Biological Treatment Technologies, v.41, p.27-34, 2001.

17 HARDER, W.; DIJKHUIZEN, L. Strategies of mixed substrate utilization in microorganisms. Journal of the Royal Society of London, v.297, p.459-480, 1982.

18 HIGARASHI, M.M. Processos oxidativos avançados aplicados à remediação de solos brasileiros contaminados com pesticidas. 1999. 96 f. Tese (Doutorado em Química Analítica), Universidade Estadual de Campinas, São Paulo, 1999.

19 JONES, J.G.; EDINGTON, M.A. An ecologic survey of hydrocarbon-oxidizing microorganisms. Journal of Genetic 
Microbiology, v.52, p.381-390, 1968

20 LIMBERT, E.S.B.; BETTS, W.B. Biodegradation of trace levels of a complex organic pollutant mixture. Journal of Microbios, v.78, p.237-243, 1994.

21 LIMA, D.; VIANA, P.; ANDRÉ, S.; CHELINHO, S.; COSTA, C.; RIBEIRO, R.; SOUSA, J.P.; FIALHO, A.M.; VIEGAS, C.A. Evaluating a bioremediation tool for atrazine contaminated soils in open soil microcosms: the effectiveness of bioaugmentation and biostimulation approaches. Chemosphere, v.74, p.187-192, 2009.

22 MANDELBAUM, R.T.; WACKETT, L.P.; ALLAN, D.L. Mineralization of the s-triazine ring of atrazine by stable bacterial mixed cultures. Appl. Environ. Microb., v.59, p.1695-1701, 1993

23 MANDELBAUM, R.T.; ALLAN, D.L.; WACKETT, L.P. Isolation and characterization of a Pseudomonas sp. that mineralizes the s-triazine herbicide atrazine. Appl. Environ. Microb., v.61, p.1451-1457, 1995.

24 MELO, I.S.; AZEVEDO, J.L. Microbiologia ambiental. 2. ed. rev. e ampl. Jaguariúna: Embrapa Meio Ambiente, 2008.

25 MERINI, L.J.; CUADRADO, V.; FLOCCO, C.G.; GIULIETTI, A.M. Dissipation of 2,4-D in soils of the humid pampa region, Argentina: a microcosm study. Chemosphere, v.68, p.259-265, 2007.

26 MURRAY, R.G.; DOETSCH, R.N.; ROBINOW, C.F. Determinative and cytological light microscopy. In: GERHARDT, P.; MURRAY, R.G.; WOOD, W.A.; KRIED, N.R. Methods for general and molecular bacteriology. Washington: American Society for Microbiology, 1994. p.21-40.

27 OSTROFSKY, E.; ROBINSON, J.; TRAINA, S.; TOUVINEN, O. Effect os cyanuric acid amendment on atrazine mineralization in surface soils and detection of the s-triazine ring-cleavage gene trzD. Soil Biology \& Biochemistry, v.33, p.1539-1545, 2001.

28 PAPANASTASIOU, A.C.; MAIER, W.J. Kinetics of biodegradation of 2,4- dichlorophenoxy-acetate in the presence of glucose. Journal Biotechnology \& Bioengineering, v. 24, p. 2001-2011, 1982.

29 PRADO, A.G.S. Efeitos provocados por agroquímicos livres ou ancorados em sílica gel na microbiota do solo. 2001. 143 f. Tese (Doutorado em Química Inorgânica), Universidade Estadual de Campinas, Campinas, 2001.

30 PRADO, A.G.S.; AIROLDI, C. Toxic effect caused on microflora of soil by pesticide picloram application. J. Environ. Monit., v.3, p.394-397, 2001.

31 RADOSEVICH, M.; TRAINA, S.J.; HAO, Y.; TUOVINEN, O. Degradation and mineralization of atrazine by a soil bacterial isolate. Appl. Environ. Microbiol., v.61, p.297-302, 1995.

32 ROQUE, M. R. A.; MELO, I. S. Isolamento e caracterização de bactérias degradadoras do herbicida diurom. Scientia Agricola, v.57, p.723-728, 2000.

33 SAMBROOK, J.; FRITSCH, E.F.; MANIATIS, T. Molecular cloning: a laboratory manual. $2^{\text {nd }}$ ed. New York: Cold Spring Harbor Laboratory Press, 1989.

34 SHALER, T.A.; KLECKA, G.M. Effects of dissolved oxygen concentration on biodegradation of 2,4-dichlorophenoxyacetic acid. Applied and Environmental Microbiology, v.51, p 950-955, 1986

35 SHAPIR, N.; MONGODIN, E.F.; SADOWSKY, M.J.; DAUGHERTY, S.C.; NELSON, K.E.; WACKETT, L.P. Evolution of catabolic pathways: genomic insights into microbial s-triazine metabolism. Journal of Bacteriology, v.189, p. 674-682, 2007.

36 SILVA, E.; FIALHO, A.M.; SÁ-CORREIA, I.; BURNS, R.G.; SHAW, L.J. Combined bioaugmentation and biostimulation to cleanup soil contaminated with high atrazine concentrations. Environ. Sci. Technol., v.38, p.632-637, 2004.

37 SMEJKAL, C.W.; VALLAEYS, T.; SEYMOUR, F.A.; BURTON, S.K.; LAPPIN-SCOTT, H.M. Characterization of (R/S)mecoprop-degrading Alcaligenes $s p$. CS1 and Ralstonia sp. CS2 isolated from agricultural soils. Environmental Microbiology,v.3, p.288-293, 2001.

38 STRONG, L.C.; ROSENDAHL, C.; JOHNSON, G.; SADOWSKY, M.J.; WACKETT, L.P. Arthrobacter aurescens TC1 metabolizes diverse s-triazine ring compounds. Appl. Environ. Microbiol., v.68, p.5973-5980, 2002.

39 VIANEZ JUNIOR, J.L.S.G. Bioinformática aplicada no desenho de iniciadores para genes funcionais - degradação do herbicida 2,4-D: um estudo de caso. 2007. 148 f. Dissertação (Mestrado em Biotecnologia Vegetal), Universidade Federal do Rio de Janeiro, Rio de Janeiro, 2007.

40 WAITE, D.T.; CESSNA, A.J.; GROVER, L.A.; SNIHURA, A.D. Environmental concentrations of agricultural herbicides: 2,4-D and Triallate. Journal of Environmental Quality, v.31, p.129-144, 2002.

41 WIDEHEM, P.; AÏT-AIISSA, S.; TIXIER, C.; SANCELME, M.; VESCHAMBRE, H.; TRUFFAUT, N. Isolation, characterization and diuron transformation capacities of a bacterial strain Arthrobacter sp. N2. Chemosphere, v.46, p.527-534, 2002. 
42 WHOLTING, C.; HANCE, R. J. (eds.) The pesticides manual: a world compendium. Farham: British Crop Protection Council (BCPC), 1991. $1141 \mathrm{p}$.

43 ZIPPER, C.; BOLLIGER, C.; FLEISCHMANN, T.; SUETR, M.J.F.; ANGST, W.; MÜLLER, M.D.; KOHLER, H.P.E. Fate of the herbicides mecoprop, dichlorprop and 2,4-D in aerobic and anaerobic sewage sludge as determined by laboratory batch studies and enantiomer-specific analysis. Biodegradation, v.10, p.271-278, 1999. 